\title{
Donald Pierson e o Projeto do Vale do Rio São Francisco: Cientistas Sociais em Ação na Era do Desenvolvimento
}

\author{
Marcos Chor Maio ${ }^{1}$ \\ Nemuel da Silva Oliveira ${ }^{2}$ \\ Thiago da Costa Lopes ${ }^{3}$
}

${ }^{1}$ Pesquisador e professor do Programa de Pós-Graduação em História das Ciências e da Saúde da Casa de Oswaldo Cruz/Fiocruz e pesquisador do Conselho Nacional de Desenvolvimento Científico e Tecnológico (CNPq). E-mail: maio@fiocruz.br

${ }^{2}$ Doutorando do Programa de Pós-Graduação em História das Ciências e da Saúde da Casa de Oswaldo Cruz/Fiocruz. E-mail: nemuel@gmail.com

${ }^{3}$ Mestre pelo Programa de Pós-Graduação em História das Ciências e da Saúde da Casa de Oswaldo Cruz/Fiocruz. E-mail: lopes_47@hotmail.com

\section{INTRODUÇÃO}

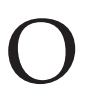

s anos 1950 foram pródigos em ciclos de pesquisas desenvolvidos pelas ciências sociais brasileiras, como o convênio Columbia University-Estado da Bahia, o programa Unesco de relações raciais e o conjunto de estudos realizados no Vale do Rio São Francisco. Patrocinados por agências nacionais e internacionais, instituições de ensino e pesquisa, os projetos abordaram um país em acelerado processo de transformação social com base na industrialização, na urbanização e em mudanças no mundo rural. No centro dessas iniciativas encontra-se tema caro à sociologia: a mudança social. Alvo de distintas interpretações, este conceito foi mobilizado por cientistas sociais no esforço de compreensão dos desafios postos pela modernização da estrutura socioeconômica do país, em que assumia relevo a ação planejadora do Estado. Neste período, o papel dos cientistas sociais foi objeto de intensos debates envolvendo os limites de seu envolvimento com a intervenção e as relações entre uma modalidade aplicada de ciência social e as atividades de natureza acadêmico-científica.

Este artigo analisa as relações entre ciências sociais e desenvolvimento no Brasil a partir da investigação do ciclo de Pesquisas no Vale do São Francisco. Coordenado pelo sociólogo norte-americano Donald DADOS - Revista de Ciências Sociais, Rio de Janeiro, vol. 56, no-2, 2013, pp. 245 a 284. 
Pierson (1900-1995), o programa de investigações foi realizado na década de 1950 sob os auspícios da Comissão do Vale do São Francisco (CVSF), da Escola Livre de Sociologia e Política (ELSP) e do Institute of Social Anthropology/Smithsonian Institution (ISA/SI). A análise recai sobre a inflexão na trajetória de Pierson, que passou da posição de sociólogo-investigador, dedicado à formação de cientistas sociais profissionais e à institucionalização das ciências sociais no Brasil - posição que se pretendia crítica e equidistante do mundo dos interesses societais e políticos - à afirmação do papel do cientista social no processo de mudança social. Para tornar inteligíveis as descontinuidades no pensamento de Pierson, representadas pelo estudo do Vale do São Francisco, assume importância o processo de profissionalização dos cientistas sociais na era do desenvolvimento, que colocou em tela os usos sociais do conhecimento socioantropológico.

O "Projeto do Vale" é geralmente inserido nos chamados "estudos de comunidade" (Melatti, 1984). No Brasil, eles constituíram um modelo explicativo da sociedade com base em múltiplas investigações empíricas, circunscritas espacialmente, de populações rurais. Seu enfoque recaiu sobre o processo de mudança em contextos sociais marcados pela tradição. Trata-se de uma abordagem que remonta aos trabalhos de cientistas sociais norte-americanos, tais como Robert e Helen Lynd (Middletown), Warner Loyd (The Social Life of a Modern Community) e Robert Redfield (Tepotzlan, a Mexican Village: A Study of Folk Life). Em termos metodológicos, os estudos de comunidade refletiriam o deslocamento, para sociedades complexas, de métodos caracteristicamente utilizados pelas pesquisas etnográficas nas denominadas sociedades primitivas.

Esses estudos foram alvo de controvérsias envolvendo, dentre outros aspectos, suas bases metodológicas e alcance explicativo, e fizeram parte dos debates em torno da institucionalização das ciências sociais, dos padrões de trabalho intelectual capazes de conferir-lhes legitimidade social e científica ${ }^{1}$. Na perspectiva positiva de autores como Florestan Fernandes (1958), ao vincularem a análise da sociedade ao levantamento sistemático de material empírico, os estudos de comunidade contribuíam para a superação das interpretações da realidade brasileira de caráter ensaístico, apresentando a diversidade sociocultural do país. 
Aos críticos, por sua vez, não faltaram observações quanto ao problema da representatividade das localidades selecionadas, tendo em vista a possibilidade de compreender, por meio desses estudos, aspectos de ordem mais geral da vida social brasileira ${ }^{2}$. Houve ainda quem sublinhasse a inadequação de seus pressupostos teórico-metodológicos, construídos a partir do enfoque antropológico sobre comunidades primitivas, e tendentes a enfatizar a estabilidade, homogeneidade e autossuficiência das estruturas sociais, em uma situação de pesquisa envolvendo uma realidade social distinta, caracterizada por uma maior fluidez e pelo contato frequente com outras localidades (Holanda, 1979 [1948]). O sociólogo Costa Pinto criticou a abordagem antropológica dos estudos de comunidade que, detendo-se na descrição dos "fatores da localidade", perdiam de vista suas conexões com a região e a estrutura social do país como um todo (1950:3). Diante do forte apelo empírico desses estudos, Caio Prado Júnior (1948) chamou a atenção para a ausência de esforços analíticos capazes de conferir inteligibilidade aos dados coligidos. Guerreiro Ramos (1995[1957]:106), por seu turno, insistindo sobre a necessidade de teorizações sociológicas globais acerca da realidade brasileira, aptas a indicar o sentido de suas transformações e servir de instrumento à construção da Nação, criticou as visadas descritivas, tópicas, transpostas acriticamente do contexto norte-americano ${ }^{3}$.

Em solo brasileiro, as investigações centradas em comunidades foram produzidas após a Segunda Guerra Mundial, no contexto do desenvolvimento, da Guerra Fria, da cooperação técnica internacional e das trocas científicas entre diferentes instituições, tais como o acordo entre o Institute of Inter-American Affairs (EUA), o Institute of Social Anthropology/Smithsonian Institution e a ELSP; a parceria entre o Serviço Especial de Saúde Pública (Sesp) e pesquisadores da ELSP no âmbito dos estudos de desenvolvimento de comunidade; os convênios entre o Programa Ponto IV do governo norte-americano, o Serviço Social Rural e a ELSP, além do programa Columbia University-Estado da Bahia. Essas iniciativas também foram apoiadas por agências multilaterais, como a Organização das Nações Unidas (ONU), a Organização das Nações Unidas para a Educação, a Ciência e a Cultura (Unesco) e a Organização Mundial da Saúde (OMS).

A análise do Projeto do São Francisco permite observar que a investigação da estrutura social de comunidades rurais passou a ser entendida, ao longo dos anos 1950, como um requisito necessário à transfor- 
mação da sociedade brasileira. O meio rural, "locus no qual o tempo passado, peculiar a uma sociedade em mudança, ainda poderia ser analisado, para que se avaliassem suas consequências no presente e no futuro", passa a ser investigado sob o prisma de sua organização social e política, suas tradições culturais e relações de trabalho (Villas Bôas, 2007:116). Dentre os estudiosos que se debruçaram sobre o impacto das mudanças no estilo e nas condições de vida das populações sertanejas, estão Emílio Willems, Antonio Cândido e Maria Isaura Pereira de Queiroz (Lima, 1999).

No "Projeto do Vale" ficou patente ainda a noção de utilidade social do conhecimento científico produzido pelos cientistas sociais. Como salientou Pierson, as pesquisas poderiam ter desdobramentos de ordem prática, associados à informação e à orientação das ações em planejamento social. A posição de Pierson, neste caso, contrasta com sua atuação na ELSP até o final dos anos 1940, quando esteve envolvido não apenas com o treinamento de estudantes em pesquisa, mas também com a tradução de textos científicos, a editoria da revista Sociologia e o trabalho de campo em Araçariguama, no interior paulista ${ }^{4}$. As pesquisas no Vale do São Francisco revelam, por outro lado, um Pierson mais atento à importância do trabalho do sociólogo no processo de desenvolvimento, ainda que sua nova perspectiva tenha sido marcada por tensões. Tratava-se da preocupação em assegurar que os fins práticos da pesquisa não influíssem negativamente sobre o desenvolvimento da análise sociológica, que se pretendia objetiva.

Em O Homem no Vale do São Francisco $(1972)^{5}$, Pierson aponta algumas diretrizes básicas destinadas à maior eficácia dos programas de intervenção, tal como o estímulo à participação ativa da população neste processo. O conhecimento da vida humana na região em seus diferentes aspectos (cultural, geográfico, econômico, histórico) era essencial aos esforços de "mudança social dirigida" (Pierson, 1972, III:475). Caberá, neste sentido, qualificar a relação estabelecida entre as ciências sociais e a conjuntura desenvolvimentista da década de 1950 no Brasil, considerando os "estudos de comunidade" e a atuação de Pierson na ELSP importantes elos que permitem articular contexto histórico e produção intelectual sobre a sociedade brasileira.

Inicialmente, o artigo examinará a origem e os objetivos do programa de pesquisas no Vale do São Francisco à luz dos planos governamentais esboçados para o desenvolvimento socioeconômico da região, que 
desde os anos 1940 vinha assumindo importância crescente na agenda política nacional, na confluência com os esforços de cooperação técnica internacional do pós-Segunda Guerra. A análise da atuação de sociólogos e antropólogos na implementação de políticas públicas no país evidencia a importância que os temas do planejamento e do desenvolvimento adquiriram para as ciências sociais no período. Em seguida, são analisadas as diferentes etapas do Projeto do São Francisco, em especial o tratamento que Donald Pierson confere ao tema da mudança social e cultural em sua obra O Homem no Vale do São Francisco. Por fim, o trabalho se concentra nos aspectos normativos da atuação de Pierson nos anos 1950 e, em particular, em suas sugestões para o planejamento social.

\section{O PROJETO DO SÃO FRANCISCO EM CONSTRUÇÃO}

Donald Pierson lecionava na ELSP há uma década quando formulou o Projeto do Vale do São Francisco em $1949^{6}$. Sua atuação na formação de sociólogos-pesquisadores e na divulgação de uma sociologia científica no Brasil inspirava-se no padrão de trabalho sociológico em vigor na Universidade de Chicago, notadamente aquele desenvolvido por William Thomas, Robert Park e Ernest Burgess, que nutriam particular interesse pelos problemas de desorganização social decorrentes dos processos de urbanização e industrialização ${ }^{7}$.

Pierson também havia organizado e dirigido o Departamento de Sociologia e Antropologia da ELSP, fundado em 1939 e transformado, dois anos depois, em Divisão de Estudos Pós-Graduados (Pierson, 1987:57). Em 1945, a Divisão, que permaneceu sob a direção de Pierson até que este deixasse o país nos anos 1950, passou a contar com um programa de treinamento em pesquisa mediante convênio com o Institute of Social Anthropology (ISA) (Anuário, 1947:14), unidade do Departamento de Etnologia Americana da Smithsonian Institution, prestigiada entidade científica norte-americana conhecida por seu vasto complexo de museus e centros de pesquisa em ciências naturais e humanas. Fundado em 1943 por iniciativa do antropólogo Julian Steward, da Universidade da Califórnia, o ISA tinha por objetivo o estímulo às atividades de ensino e pesquisa em ciências sociais em países latino-americanos, tendo por base a cooperação entre pesquisadores norte-americanos e instituições acadêmicas locais. Steward nutria particular interesse pelo problema da mudança nos padrões culturais de grupos indígenas 8 .

DADOS - Revista de Ciências Sociais, Rio de Janeiro, vol. 56, nº 2, 2013 
As atividades do ISA foram financiadas pelo Departamento de Estado norte-americano no contexto da política de "boa vizinhança" do Governo Roosevelt. Os programas de pesquisa em antropologia da instituição previam a realização de estudos em comunidades rurais em processo de transformação. Os trabalhos "ficariam disponíveis a planejadores nos vários países em que as pesquisas fossem realizadas, e proveriam os dados socioculturais de que necessitam" (Foster, 1979 [1967]:205, tradução livre).

No Brasil, os representantes do ISA foram Donald Pierson e o antropólogo Kalervo Oberg ${ }^{9}$. A atuação de Pierson na ELSP foi central para o estabelecimento de atividades financiadas pelo ISA no país e também serviu de modelo à criação de convênios entre o órgão norte-americano e instituições acadêmicas em países como México, Peru e Colômbia (Pierson, 1987:42; Price, 2008:112).

O ISA foi um dos patrocinadores do programa de pesquisas no Vale do São Francisco, cujo objetivo era o estudo detalhado do modo de vida de suas populações, levando-se em conta as características físico-geográficas da região e as dimensões históricas, econômicas e socioculturais de suas comunidades (Pierson, 1972, III:446). Em um documento destinado ao ISA, intitulado "Notes on the São Francisco Preliminary Survey", Pierson chamou a atenção para três pontos do projeto de pesquisa:

\section{A. Científico:}

1. Fornecerá dados preliminares para fins comparativos;

2. Provavelmente estimulará (e talvez venha a ser modelo) para surveys em outras partes do Brasil;

\section{B. Prático:}

1. Fornecerá dados úteis ao planejamento social no vale, por parte dos funcionários públicos responsáveis por melhorias na saúde, saneamento, agricultura, educação etc.;

2. Contribuirá no acompanhamento e na avaliação das prováveis mudanças sociais no futuro próximo, especialmente com o amadurecimento dos planos do governo federal para desenvolver a capacidade hidroelétrica do vale;

C. Estratégico:

1. Ao fornecer informações úteis a outras pessoas e organizações no Brasil, chamará a atenção para a Escola [de Sociologia e Política], seus objetivos, realizações e possibilidades de colaboração futura; 
2. Empregando neste caminho - num projeto fora do estado de São Paulo e de interesse nacional - parte do financiamento recentemente concedido à Escola pelo governo federal, ajudará a justificar, aos olhos dos legisladores federais, a subvenção federal à Escola, e aumentará a probabilidade de sua renovação, e seu aumento, no futuro ${ }^{10}$.

Do ponto de vista científico, Pierson tinha como meta reunir dados sobre importante região do país e, com base em análises comparativas, produzir conhecimento sobre as diversas comunidades. Segundo o sociólogo, o contato íntimo com realidades sociais específicas era o único meio possível para generalizações em ciência. Daí o avanço da profissionalização da sociologia depender, a seu ver, da ampliação da prática de pesquisa sistemática. Neste caso, era fundamental garantir recursos para a ELSP, o que remete ao aspecto "estratégico" do Projeto do São Francisco. O fornecimento de informações úteis a órgãos governamentais tornaria o Estado sensível às atividades científicas da instituição com o respectivo apoio financeiro ${ }^{11}$.

O "Projeto do Vale" servia, assim, à legitimação de um padrão de trabalho sociológico calcado na investigação empírica, conduzida por equipes de pesquisadores treinados, em face não somente da comunidade de cientistas sociais que então se formava ${ }^{12}$, mas também do poder público. No item $B$ do documento, que tratava do aspecto prático do projeto, Donald Pierson destacou, seguindo esta linha de raciocínio, a importância da cooperação entre cientistas sociais e Estado na área do planejamento social.

\section{PESQUISA, PLANEJAMENTO E DESENVOLVIMENTO NO CICLO DE ESTUDOS DO VALE DO SÃO FRANCISCO}

Nos anos 1940 e 1950, em um contexto de vertiginosas transformações do país, a ideia de planejamento tornou-se recorrente no discurso de economistas, industriais e técnicos. A aposta no planejamento, pensado como um conjunto de ações estratégicas no setor econômico, implicava a intervenção deliberada e programada do Estado no processo de industrialização, a partir da perspectiva de que as forças econômicas seriam incapazes de conduzir espontaneamente a superação do atraso (Bielschowsky, 1995) ${ }^{13}$.

A possibilidade de exercer controle sobre os processos de mudança com base em planos de ação também atraiu cientistas sociais como Luiz de Aguiar Costa Pinto e Florestan Fernandes. Apoiando-se em 
Mannheim, que punha em relevo o papel do intelectual na remodelação da sociedade, eles atribuíram a si mesmos a tarefa de auxiliar na construção de uma ordem moderna no Brasil (Villas Bôas, 2006). Afirmando que a reflexão sociológica passava necessariamente pelo envolvimento do investigador com a vida social, Costa Pinto observa que

a forma mais autêntica e mais expressiva dos homens refletirem uma mudança social na qual estão envolvidos é tomar consciência dela, tentar compreendê-la e interpretá-la, formular programas de ação que visem controlá-la e organizar agências específicas por meio das quais vão ensaiar aquele supremo objetivo de predeterminar o futuro pela ação no presente (Costa Pinto, 1953:230).

Costa Pinto acreditava que a sociologia era fundamental no debate sobre os desafios do desenvolvimento no contexto brasileiro, uma vez que era preciso atentar tanto para as condições sociais do avanço econômico quanto para as suas implicações sociais, seus efeitos sobre a estrutura de classes (Sorj, 1999:226). Para Florestan Fernandes, a formulação de "uma política de controle e orientação, na medida do possível, dos processos sociais" deveria ter como base técnicas sociologicamente informadas (Fernandes, 1979:164). No tocante à centralidade das ciências sociais nas tarefas de planejamento, Donald Pierson se aproxima dessas perspectivas. As pesquisas no Vale do São Francisco serviriam à avaliação e ao acompanhamento das mudanças nas relações sociais e na cultura das comunidades, impulsionadas, por sua vez, pela intervenção estatal na região.

O interesse econômico-social do governo brasileiro pelo Vale torna-se evidente no pós-Segunda Guerra. Caberia intervir de forma centralizada e racional na região com o fito de realizar um bem-sucedido processo de ocupação e desenvolvimento. Esta iniciativa inspirou-se no Tenessee Valley Authority (TVA), órgão criado na era Roosevelt, que se tornou fonte inspiradora em planejamento e administração de áreas rurais pobres. O São Francisco, tradicionalmente concebido como o rio da "integração nacional", era alvo de iniciativa pioneira de planejamento regional (D'Araújo, 1992). No artigo 29 da Constituição de 1946, é destacada a importância de se definir o traçado e a execução de "um plano de aproveitamento total das possibilidades econômicas do rio São Francisco e seus afluentes, no qual [o governo federal] aplicará, anualmente, quantia não inferior a um por cento de suas rendas tributárias" ${ }^{14}$. No processo de elaboração do plano foi criada a Comissão do 
Vale do São Francisco (CVSF) pela Lei Federal no 541, de 15 de dezembro de 1948, que, dentre outras questões, estabeleceu:

Art. $7^{\circ}-$ Incumbe à C.V.S.F.:

a) organizar e submeter ao presidente da República, para aprovação do Congresso Nacional, o plano geral de aproveitamento do Vale do São Francisco, que vise à regularização do curso de seus rios, melhor distribuição de suas águas, utilização de seu potencial hidroelétrico, fomento da indústria e da agricultura, desenvolvimento da irrigação, modernização de seus transportes, incremento da imigração e da colonização, assistência à exploração de suas riquezas.

Art. 9o - A Comissão poderá colaborar com as associações rurais, já constituídas ou que se venham a criar, no sentido de introduzir na agricultura e na pecuária, ou de os aperfeiçoar, os processos mais rápidos e eficientes.

Art. $10^{\circ}$ - A C.V.S.F., ao organizar suas tabelas de salários, procurará fixá-los observadas as condições de cada região, a fim de atenuar quando possíveis as perturbações oriundas da mudança de atividade das populações locais ${ }^{15}$.

Na alínea "a" do documento fica evidenciado que o principal interesse da administração pública recaía sobre a indústria, a agricultura e a exploração de recursos naturais. Era fundamental promover incrementos tecnológicos (tais como irrigação, uso de fertilizantes e maquinário industrial) capazes de acelerar o desenvolvimento econômico da região em um processo de modernização especialmente ligado à produção de energia hidrelétrica ${ }^{16}$. O engenheiro civil Lucas Lopes ${ }^{17}$, chefe da equipe dos técnicos responsáveis pelo "plano geral", destacou a importância estratégica, do ponto de vista geopolítico, da valorização econômica do Vale. O povoamento das margens do São Francisco, a elevação do padrão de vida das populações ribeirinhas e o aumento do intercâmbio das regiões Nordeste e Sudeste seriam fundamentais para a consolidação da unidade nacional (Lopes, 1955:30).

Nota-se ainda a preocupação com alterações na ordem social que transformações no setor econômico poderiam suscitar. No caso do aproveitamento hidrelétrico do São Francisco, que exigia o alagamento de extensas áreas para a construção de barragens, comunidades inteiras seriam deslocadas de suas terras, o que aumentaria o fluxo migratório para regiões vizinhas e outras áreas do país. Esse processo poderia desencadear "perturbações", conforme expressão da referida lei, 
envolvendo tanto conflitos sociais em torno da disputa de terras como problemas de adaptação da população às novas áreas, decorrentes de mudanças nos hábitos alimentares, nas atividades de trabalho e nas relações vicinais (Camelo Filho, 2005:88).

Para os técnicos do Estado, conhecer as populações do Vale do São Francisco era um passo importante rumo à superação dos entraves de natureza sociocultural ao desenvolvimento por meio de ações planejadas. Eles concebiam esse processo não apenas mediante o aumento da produtividade na esfera do trabalho, mas também pela elevação dos padrões educacionais e sanitários da região.

\section{O PAPEL DAS CIÊNCIAS SOCIAIS NOS PROGRAMAS DE DESENVOLVIMENTO REGIONAL}

$\mathrm{Na}$ arena internacional, o discurso sobre o desenvolvimento surgiu no pós-guerra como um conjunto de representações e práticas no âmbito das relações entre povos e sociedades. Ele operou a redefinição da situação das ex-colônias e nações periféricas, que à luz dos padrões civilizacionais dos países afluentes do mundo ocidental passaram a ser vistas como "pobres" e "subdesenvolvidas" (Escobar, 1996). Tendo como pressuposto a noção de continuidade histórica, de destino comum entre as diferentes regiões do globo, este discurso definiu como prioritária a luta contra o atraso daqueles países (Rist, 2002) ${ }^{18}$.

Um dos alicerces da era do desenvolvimento foi o advento do programa Ponto IV, criado em 1949, durante o governo Truman. Ele estabelecia o uso dos recursos técnico-científicos norte-americanos no combate à pobreza nos países periféricos, na melhoria de seus aspectos econômicos, sociais e sanitários ${ }^{19}$. Tratava-se de um amplo empreendimento que, apelando à cooperação internacional, à assistência técnica, visava à elevação das condições de vida das populações locais e ao aumento das zonas de influência norte-americana no âmbito da Guerra Fria, em face do avanço do comunismo (Lleys, 2005; Packard, 1997; Cueto, 2007).

No Brasil, durante o segundo governo Vargas, a emergência de uma perspectiva desenvolvimentista esteve ligada à crença de que o avanço do país dependia da construção de uma sociedade capitalista de tipo industrial (Bielschowsky, 1995; Cepêda, 2012). Visto como ator fundamental neste processo, o Estado brasileiro passa a adotar nos anos 1950, políticas de desenvolvimento destinadas à correção das desi- 
gualdades e assimetrias regionais do país, valendo-se principalmente de investimentos em infraestrutura básica (Costa Lima, 2011). No campo da saúde, o período foi marcado pelo otimismo sanitário, pela crença de que inovações tecnológicas do setor contribuiriam decisivamente no combate às doenças endêmicas, alavancando a economia local (Hochman, 2009).

Neste contexto, diferentes programas de desenvolvimento contaram com a participação de cientistas sociais. Este foi o caso do antropólogo norte-americano Charles Wagley, da Universidade de Columbia, que foi funcionário do Sesp durante a Segunda Guerra e participou, nos anos 1940, do projeto de criação de um centro de pesquisas interdisciplinar de caráter global denominado Instituto Internacional da Hileia Amazônica sob os auspícios da Unesco (Maio e Sá, 2000; Maio e Oliveira, 2010). Ele conduziu trabalho de campo no município de Gurupá. Em conferência proferida no Institute for Brazilian Studies da Universidade de Vanderbilt, em 1950, Wagley afirmou que os fatores humanos representados pela sociedade e cultura locais eram os principais entraves ao aproveitamento eficaz de seus recursos naturais, de grande potencial econômico (Wagley, 1951). O antropólogo se referia aos compromissos firmados pelo governo norte-americano, por ocasião do Ponto IV, de fomento aos programas de desenvolvimento nas regiões "atrasadas" do globo:

O que nós concebemos como "racional" e "eficiente" pode não parecer desta forma, ou realmente pode não ser desta forma, nos termos de uma outra cultura. Nem a cultura é transmitida mecanicamente como um carregamento de mercadorias de uma cultura para outra. O problema de "tornar os benefícios do nosso conhecimento científico disponível [...] para nações subdesenvolvidas" proposto pelo presidente Truman é mais complexo do que simplesmente torná-lo "disponível". Não é suficiente enviar especialistas para as regiões a fim de recuperar terras, construir pontes, instalar fábricas, e assim por diante, nem é suficiente treinar grande número de pessoas da localidade em questão nos nossos métodos. O novo conhecimento, as novas ferramentas, e as demais inovações devem se fazer aceitáveis para a população em seus próprios termos (ibidem:21, tradução livre).

Segundo Wagley, a transferência de tecnologia das nações ricas para as subdesenvolvidas, um dos objetivos delineados pelo Ponto IV, era geralmente pensada de forma impositiva, sem que fosse devidamente considerado o problema da incorporação, pelas populações locais, dos 
padrões culturais ocidentais. Investidos de uma visão que privilegiaria sobremaneira a dimensão cultural (códigos de conduta, sistema de crenças, rituais, costumes, normas, valores, linguagem), os antropólogos seriam capazes de aquilatar as implicações, em termos de reações e conflitos, que inovações técnicas em determinado setor da vida social podiam acarretar em outros. Isto porque, com frequência, a integração efetiva à cultura local exigia a remodelação dos novos elementos (idem:27). No caso da Amazônia, a expectativa de Wagley, sensível ao caráter assimétrico que pautava as relações entre nações centrais e periféricas, era de que uma nova cultura emergisse, "combinando as forças produtivas da ciência e da tecnologia modernas com os valores humanos positivos e a íntima adaptação ao ambiente da cultura presente" (idem:30).

No início dos anos 1950, coube a Wagley, junto ao antropólogo Thales de Azevedo (Universidade Federal da Bahia) e ao sociólogo Luiz de Aguiar Costa Pinto (Faculdade Nacional de Filosofia da Universidade do Brasil), a direção do projeto Columbia University-Estado da Bahia, elaborado durante a gestão de Anísio Teixeira na Secretaria de Educação e Saúde, no governo de Otávio Mangabeira (1947-1951). Tendo por objetivo o planejamento de políticas nos setores educação e saúde, o projeto envolveu a realização de estudos sociológicos e antropológicos cujo enfoque recaía sobre a dinâmica da mudança cultural em curso em diferentes localidades (Maio, 2009). A difusão de "moderna tecnologia" na região estava ligada à construção de escolas rurais, postos de higiene e rodovias. Também era crescente a presença do rádio, do avião e do cinema e, com a instalação da usina hidrelétrica de Paulo Afonso no Baixo Rio São Francisco, diversas cidades receberiam eletricidade (Wagley et alii, 1950:9-10).

Os estudos deveriam ser conduzidos com base na cooperação entre administradores e cientistas sociais "no sentido da solução dos problemas sociais" (ibidem:7). Esperava-se que os técnicos em saúde e educação participassem do próprio desenho das pesquisas, apontando questões de caráter prático que pudessem ser esclarecidas junto aos cientistas sociais no decorrer da investigação (idem:20-21). Uma delas dizia respeito às "barreiras" a serem vencidas em se tratando das concepções vigentes sobre doença, a fim de que um "conceito científico de medicina" pudesse ser incorporado pela população.

A necessidade de se considerar, no processo de intervenção social, os padrões culturais das populações locais também foi objeto de reflexão 
de cientistas sociais em atividade no Sesp. Criado em 1942, a partir do programa de cooperação técnica do Instituto de Assuntos Interamericanos (IAIA), o Sesp foi produto da parceria entre o governo brasileiro e o norte-americano como parte dos esforços de guerra. Após o conflito, o órgão manteve-se em funcionamento devido ao apelo que suas ações sanitárias tiveram para projetos de desenvolvimento regional, como aquele levado a cabo no Vale do São Francisco (Campos, 2006).

A partir de 1953, a Divisão de Educação Sanitária do Sesp contou com uma Seção de Pesquisa Social, criada e dirigida pelo sociólogo José Arthur Rios. Um dos objetivos de Rios, ligado ao trabalho de educação rural, foi o de orientar profissionais de saúde no trato com as populações locais a fim de vencer as resistências culturais à mudança. Por conhecerem o universo cultural das populações-alvo dos programas sanitários, os cientistas sociais poderiam atuar como "intérpretes" ou "mediadores" entre aquelas e os profissionais de saúde (Rios, 1953:2). Eles deveriam "alertar o administrador para o problema do ritmo e da amplitude da mudança que este quer provocar, a fim de que aquilo que se propõe como um progresso não se transforme em crise" (ibidem:3).

O antropólogo canadense Kalervo Oberg, ao comentar os resultados de sua pesquisa na comunidade de Chonin de Cima (MG), contemplada pelas atividades do Sesp, atribuiu aos cientistas sociais a tarefa de definir as prioridades no processo de intervenção. A seu ver, esses profissionais também cumpriam importante papel no envolvimento da própria comunidade com os programas governamentais. Isto porque era preciso trabalhar "de dentro da comunidade, em vez de tentar impor de fora serviços de saúde, educação e agricultura" (Oberg, 1961:49). O compromisso do cientista social, do "pesquisador de comunidade", com as ações em saúde e educação revelava assim forte conotação política: "Os serviços são necessários, mas seu valor tem que ser real para as comunidades rurais, e vice-versa: os serviços precisam saber o que o povo rural pode e deseja aceitar. É precisamente aqui que os pesquisadores de comunidade são necessários. Trabalhando com o povo, eles podem esclarecer suas necessidades, suas aspirações e seus problemas" (ibidem:49).

Essas experiências na esfera das ciências sociais aplicadas denotam uma face das pesquisas socioantropológicas nos anos 1940 e 1950 intimamente articulada à preocupação com a fundamentação científica de políticas públicas e de programas de desenvolvimento regional. Foi neste contexto, marcado pela aproximação de cientistas sociais das 
ações do Estado, que Donald Pierson coordenou a execução do programa de pesquisas no Vale do São Francisco.

\section{CIENTISTAS SOCIAIS EM CAMPO: AS PESQUISAS NO VALE DO SÃO FRANCISCO}

A realização do "Projeto do Vale" envolveu duas etapas: um survey, capaz de proporcionar aos pesquisadores uma visão geral sobre a região, e estudos sistemáticos nas localidades. As atividades iniciais do projeto incluíram: 1) o exame da literatura disponível sobre o Vale; 2) uma viagem pelo curso do rio para observar a realidade das comunidades ribeirinhas, entrevistar a população e coletar dados quantitativos; 3 ) a elaboração de relatórios sobre as atividades desenvolvidas (Pierson $e t$ alii, 1952:22-23). A duração prevista para a condução das pesquisas foi de oito meses $^{20}$.

Donald Pierson e dois de seus ex-alunos da ELSP, Octavio da Costa Eduardo e Levy Cruz, fizeram a primeira viagem ao Vale do Rio São Francisco entre os meses de abril e junho de 1950, percorrendo os quase $2.200 \mathrm{~km}$ da região - da nascente até a foz do rio - em barcos, canoas, caminhões e, algumas vezes, a pé21. O financiamento do survey foi acordado entre Pierson e Jaime Duarte, técnico em educação da CVSF, por intermédio de Anísio Teixeira ${ }^{22}$. Na ocasião, a CVSF solicitou que os pesquisadores dedicassem especial atenção à educação e à medicina popular no Vale (Pierson et alii, 1952). Os resultados parciais do survey reforçaram a importância da pesquisa empírica para a "eficiência do planejamento social" (ibidem:24).

O material coligido serviu ainda de base à seleção das comunidades que seriam alvo das investigações em profundidade. Elas foram escolhidas em pares $^{23}$ que deveriam refletir a diversidade da região em termos físicos (um par próximo da nascente do rio, outro na região das corredeiras, outro, ainda, próximo da foz); econômicos (uma área predominantemente agrícola, outra pecuarista ou comercial); e socioculturais (variações do contato com os centros urbanos) (Pierson, 1972, I:57-103) ${ }^{24}$.

Na elaboração de seu programa de pesquisas, Pierson foi influenciado por Robert Park, Ernest Burgess e Robert Redfield (Pierson, 1987:33-34). A marca da Escola de Chicago é evidenciada em carta a Paulo Peltier de Queiroz, diretor-superintendente da CVSF. Neste documento, que resume sua agenda de trabalho, o sociólogo se refere à 
"'luta pela existência', e suas consequências com referência às formas culturais e à migração"; ao papel do isolamento e do contato na organização social, "das relações entre pessoas famílias, raças e nacionalidades" e "das formas e grau de intensidade do conflito e acomodação", destacando, ainda, o problema relativo "ao caráter, à dimensão e à intensidade da mudança social que começa a aparecer em certas áreas do vale $^{\prime 25}$. Estes temas eram caros à sociologia de Park e Burguess, a exemplo do processo ecológico de conformação das comunidades e da dinâmica das interações de grupos de diferentes matrizes étnicas e culturais ${ }^{26}$.

O grau de "isolamento" e "contato" das comunidades locais em relação aos centros urbanos constitui uma das ideias diretrizes do estudo. A principal hipótese de pesquisa de Pierson indica que quanto mais isolada uma comunidade, menor seria a importância da mudança social em seu interior e mais evidente a força da tradição. Assim, o curso e o grau da mudança que se operava em cada comunidade podiam ser avaliados com base na identificação do ponto em que ela se situava no continuum rural-urbano, ou ainda, na medida em que sua organização social se aproximava ou se afastava de um dos extremos do gradiente cultura de folk-civilização, par conceitual que remete aos estudos do antropólogo Robert Redfield na Península de Yucatã, no México ${ }^{27}$.

Segundo Redfield, o conceito de "cultura de folk" envolvia a identificação de estruturas sociais homogêneas, de base rural, em que a família e o parentesco são os principais determinantes dos laços de solidariedade social entre os indivíduos. Seu sistema de crenças, atitudes e sentimentos são de natureza mágico-religiosa. O conceito de "civilização", por seu turno, é construído em oposição àquele e denota estrutura social mais heterogênea e diferenciada, com predomínio de valores impessoais, do interesse e da conveniência na vida associativa dos indivíduos. Na "cultura de folk", de natureza estável, o indivíduo é refém da tradição, que consegue se perpetuar ao longo do tempo e das gerações na medida em que se mantém mais ou menos isolada de outras sociedades. Em contraposição, a "civilização" seria melhor exemplificada pelas grandes metrópoles, marcadas pelo contato entre diferentes povos e culturas e por constantes transformações sociais (Redfield, 1949).

Estruturado em torno dessas ideias e problemas, o Projeto do São Francisco foi apresentado ao Departamento de Produção e Assistência da CVSF em 30 de dezembro de 1950, após a realização do survey. Ao encaminhar o Projeto para apreciação do presidente Eurico Gaspar Dutra, a 
diretoria da CVSF apontou a necessidade de que órgãos públicos e privados conhecessem os "processos sociais de manutenção, transmissão e desenvolvimento da cultura de uma área tão estrategicamente importante para o país como o Vale" 28 . O documento considerava o Projeto "a base indispensável em que se alicerçará a política governamental de assistência às populações e amparo à produção", reafirmando, desse modo, a crença dos técnicos quanto ao valor das ciências sociais na orientação das intervenções (ibidem). Embora tenha inicialmente lançado mão de políticas econômicas de feição liberal, o Governo Dutra caracterizou-se por iniciativas no âmbito do planejamento regional, além de ter esboçado um plano nacional de investimentos públicos nos setores saúde, alimentação, transporte e energia (SALTE) (Skidmore, 1976).

Ao patrocinar o programa de pesquisas capitaneado por Pierson, a CVSF estava a par de experiências internacionais no campo das ciências sociais aplicadas, a exemplo do estudo no Haiti realizado pelo antropólogo Alfred Métraux, funcionário do Department of Social Affairs da ONU (Maio, 1997), "inquérito sociológico e ecológico" que serviria de "anteparo e apoio de qualquer ação governamental" 29 . A pesquisa de Métraux (1948) integrou um projeto da Unesco levado a cabo em 1948, com a colaboração da OMS, da FAO e do governo haitia$\mathrm{no}^{30}$, visando à elevação do padrão de vida no Vale do Marbial, área rural com cerca de 30 mil habitantes, mediante técnicas modernas de educação fundamental ${ }^{31}$. Foi a primeira iniciativa de assistência técnica da ONU em uma área subdesenvolvida (Amrith e Sluga, 2008:261-262). O conhecimento da CVSF acerca de pesquisas como esta, na interface com projetos de desenvolvimento, indica o impacto da atuação de agências internacionais na modelagem de projetos locais.

\section{O HOMEM NO VALE DO SÃO FRANCISCO}

A segunda etapa do Projeto do Vale do São Francisco foi um empreendimento coletivo de estudos nas comunidades, em que participaram 21 pesquisadores e assistentes de pesquisa, divididos em cinco equipes (Pierson, 1972, I:7-12). Cada uma permaneceu no Vale de quatro a seis meses. O estudo se estendeu de janeiro de 1952 a outubro de 1953. Estes dados revelam a magnitude do programa de pesquisas coordenado por Pierson. Além de ter sido a base de diversas monografias, o material produzido foi utilizado na elaboração d'O Homem no Vale do 
São Francisco (1972), obra dividida em três volumes que contempla todas as comunidades estudadas e revela o esforço de Pierson em compreender o processo de mudança social em curso na região ${ }^{32}$.

No primeiro volume, Pierson descreve os aspectos físicos da região: a bacia hidrográfica do rio São Francisco, formação geológica, clima, vegetação e fauna. É o momento da narrativa da chegada do sociólogo às diversas localidades e das dificuldades de transporte para alcançá-las (Pierson, 1972, I:59-94). Também apresenta informações sobre a história do Vale, desde a chegada dos europeus no início do século XVI até as primeiras décadas do século XX (ibidem:223-224). O contato entre populações indígenas, colonizadores europeus e africanos escravizados estaria na origem de um conjunto de crenças e hábitos alimentares e de saúde, padrões de comportamento e técnicas de trabalho constitutivo das tradições populares do presente $^{33}$.

No segundo volume são abordadas as bases ecológicas da vida social no Vale bem como seu perfil demográfico ${ }^{34}$. As atividades econômicas predominantes ligavam-se à pecuária, à agricultura de subsistência (arroz, mandioca), à caça e à pesca (Pierson, 1972, II: 293-295). A maioria da população morava em casas de pau-a-pique, divididas em média em dois cômodos com pouco mobiliário (ibidem:97-121).

No terceiro volume, Pierson trata da vida associativa e do universo cultural das comunidades a partir de questões como repertório de etiquetas sociais, laços de parentesco, rituais, crenças morais e religiosas e comportamento político, além do processo de socialização do indivíduo, de assunção de papeis sociais na comunidade. As práticas socialmente valorizadas tendiam a reforçar a solidariedade em torno do grupo familiar, unidade social básica em todo o Vale, à qual se somavam as relações vicinais e de compadrio, que influíam sobremaneira no comportamento dos indivíduos (Pierson, 1972, III:5-27).

Percorrendo as diferentes dimensões da vida humana no Vale, o estudo de Pierson detém-se na análise da mudança social. Sua hipótese explicativa relaciona-a ao rompimento do isolamento geográfico e cultural das comunidades, à sua gradativa inserção no mundo urbano. Os resultados deste processo, que convergiam para a formação de uma sociedade moderna, não sendo completamente observados no presente, eram apresentados enquanto as "tendências" mais prováveis de desenvolvimento das comunidades. Pierson destaca ainda o ritmo lento 
da mudança e os ruídos que ocasionavam, relativos aos fenômenos da resistência cultural e da desorganização social das comunidades.

As transformações eram perceptíveis na estrutura socioeconômica, até então predominantemente rural, autossuficiente e pouco diversificada. Na comunidade de Cerrado, sob a influência do centro urbano de Belo Horizonte, novos estabelecimentos comerciais começaram a surgir, responsáveis pela disseminação de artigos manufaturados em substituição aos produtos artesanais utilizados pela população, especialmente os têxteis. O crescimento das transações comerciais gerava maior especialização das atividades ocupacionais, modificando o padrão dos vínculos empregatícios (especialmente com o afrouxamento dos laços tradicionais entre senhores de terra e trabalhadores rurais) e tornando o dinheiro item cada vez mais importante na localidade (Pierson, 1972, III:461-462). Embora predominassem empregos agropecuários, crescia o volume de ocupações urbanas: médicos, advogados, funcionários públicos, professores, motoristas de caminhão etc. (Pierson, 1972:293-338).

A construção da hidrelétrica de Paulo Afonso e o aumento da distribuição de energia elétrica permitiram o uso de novas tecnologias que influíram diretamente sobre a produtividade econômica, como o sistema de irrigação com bombas d'água e o arado mecânico ${ }^{35}$. O poder público vinha ainda construindo estradas na região e estendendo o serviço aéreo a várias cidades. A presença crescente de caminhões desempenhava importante papel não apenas no transporte de cargas e pessoas, mas também na disseminação de notícias, como meio de comunicação entre as localidades mais afastadas e os centros urbanos (Pierson, 1972, II:583-589). O advento do rádio abria "um novo mundo a um crescente número de pessoas nas cidades e em maiores fazendas, pessoas que estiveram outrora isoladas em graus variados não apenas geográfica, mas costumeira e psiquicamente" (ibidem:459).

A avaliação do ritmo da mudança sociocultural é patente nos capítulos sobre higiene, doenças e práticas de cura. Pierson indica que, embora os serviços de saneamento básico fossem precários, a CVSF vinha trabalhando para a extensão do fornecimento de água encanada a comunidades ribeirinhas (idem:143-155). Também era visível a atuação do Serviço Especial de Saúde Pública, com a instalação de postos de saúde, e do Serviço Nacional de Malária, responsável pelas campanhas de dedetização ${ }^{36}$. 
Nos cuidados com o corpo, as práticas de folk predominavam, com o uso chás, unguentos, infusões, óleos e ceras, por vezes acompanhadas de benzeduras, orações, amuletos e dietas. Crescia, no entanto, a influência do "sistema de ideias, atitudes, práticas e especialistas de origem urbana e mais sofisticada do mundo externo" (Pierson, 1972, III:452). Era cada vez mais frequente a utilização de soro antiofídico em substituição aos serviços dos "curadores-de-cobra" (ibidem:196), e algum grau de ceticismo já se fazia notar em relação ao poder dos curandeiros (idem:258). Nas localidades menos isoladas, a população mostrara entusiasmo pelas ações governamentais de combate ao mosquito transmissor da malária ${ }^{37}$ (Pierson, 1972, II: 264-265), enquanto os habitantes "mais bem informados" buscavam aproveitar os recursos farmacêuticos disponíveis nos postos de saúde locais, tais como vermífugos e antibióticos, por vezes utilizados indiscriminadamente (ibidem:266-268).

O grau de incorporação de concepções científicas em saúde variava de acordo com fatores como local de residência, classe social e família. Elas coexistiam, no imaginário social, de modo conflitante com concepções tradicionais. A resistência cultural à mudança era perceptível nas atitudes de reserva, e por vezes de hostilidade, para com os profissionais de saúde. Um pescador afirmou que não se contentava apenas com os médicos locais. Tendo acumulado experiências malsucedidas de tratamento, afirmava que eles "frequentemente não [sabiam] o que receitar" (idem:270). A resistência era maior no caso de pacientes do sexo feminino. O exame médico, em sua maioria a cargo de homens, esbarrava no tabu da exposição do corpo da mulher fora do contexto conjugal (idem:274). Tais problemas, decorrentes de uma "falta de uma tradição de médicos na cultura local", agravam-se pela incompreensão destes, pouco sensíveis à influência do sistema tradicional de crenças sobre o comportamento dos indivíduos (idem:269) ${ }^{38}$.

A análise do processo de educação formal também lança luz sobre o tema das resistências ${ }^{39}$. A relação entre escola e comunidade era permeada por tensões: esta não compreendia os propósitos do ensino ou não enxergava nele qualquer valor utilitário "para garantir o sucesso do indivíduo na luta pela vida" (Pierson, 1972, III:336). A eficácia do processo educacional, garantindo a frequência escolar, dependia de sua maior ou menor integração ao restante da vida comunitária. À escola faltava o respaldo de "todos os aspectos da cultura local e, em especial, [das] atitudes de pessoas da comunidade que gozam de prestígio aos olhos da criança" (ibidem:394) ${ }^{40}$. 
A despeito da influência decisiva da família na vida do indivíduo, seu controle social vinha se enfraquecendo com o passar do tempo (idem:29-35). Era o que se observava na esfera política, com a diminuição da força do parentesco na obtenção e manutenção do poder local. $\mathrm{O}$ declínio do papel político do grande fazendeiro seria concomitante à emergência de novas lideranças entre professores e médicos formados nas grandes cidades, cujo comportamento político gozava de mais independência frente aos antigos vínculos familiares. A redução da violência e da coerção típicas do coronelismo significava "mudanças em direção a uma ordem mais democrática" (idem:288-290). Isto é, a "lealdade [dos novos líderes] à cidade e à área circundante começa[va] a suplantar a lealdade ao grupo de parentesco e ao partido", abrindo espaço para a efetiva participação política de "eleitores menos facilmente controlados", inclusive entre as classes baixas (idem:290-291).

Aos olhos de Pierson, a mudança social se insinuava lentamente na diminuição da homogeneidade da estrutura socioeconômica, acompanhada, no plano dos valores, pela adoção do individualismo; pela contestação do "tradicional orgulho de família" em nome da igualdade e pelo ceticismo crescente diante das crenças mágicas. Tratava-se da gradativa substituição de uma ordem social "tradicionalmente rural, pastoril, agrícola, e orientada em termos de hierarquia", por outra, baseada "em princípios mais igualitários, com maior diferenciação econômica, política e sociológica" (idem:462). Para o sociólogo, o "problema básico prático de natureza sociológica ou socioantropológica no Vale" dizia respeito à incorporação apenas parcial dos padrões culturais modernos por parte da população, principalmente pelos setores populares (idem:465). O isolamento explicava o "atraso" das comunidades, em cujo interior ainda vigiam elementos culturais "parcial ou inteiramente derivados de fontes medievais européias, ameríndias, africanas [...] e transmitidas de geração a geração por habitantes não alfabetizados" (idem).

A efetiva transformação social dependia de um processo amplo, que pusesse em movimento as diferentes partes constitutivas da comunidade. Tomando a sociedade como um todo orgânico, Pierson afirma que a alteração que se desejava produzir nos campos da educação e da saúde tornava imperativa a consideração dos demais aspectos da vida comunitária, sob o risco de a força das tradições sobrepujar as novas práticas, crenças e instituições que começavam a ser introduzidas (idem:472). 
A mudança detinha igualmente um sentido, apontando para a conformação gradativa das comunidades ao padrão societário e político dos centros urbanos ou, no dizer de Pierson, aproximando-se da ideia de "civilização". Ainda que não utilize o termo "desenvolvimento", a visão de Pierson sobre a integração da população a "uma ordem tecnológica e cultural do século $X X$ " não se restringiu a considerações sobre o incremento da atividade econômica ${ }^{41}$. É significativo que o sociólogo tenha considerado indícios de mudança tanto as alterações nas relações políticas locais em direção a uma ordem democrática, quanto a diminuição do controle social familiar sobre o comportamento individual.

Ainda que afirme o caráter tipo-ideal de seus conceitos (Pierson, 1941), o autor por vezes se torna refém dos esquemas abstratos ao analisar a mudança. Unidirecional, o curso histórico parece conduzir as comunidades inexoravelmente à adoção dos traços tidos como definidores da sociedade moderna ${ }^{42}$. Por mais que se constate a existência de tensões neste processo, provenientes do sistema cultural, o aparato conceitual de Pierson, tomado de empréstimo a Redfield, não será problematizado à luz do fenômeno da permanência ou reatualização do atraso. A mudança acaba sendo abordada em uma chave dualista ou disjuntiva, com o "moderno" implicando a substituição do "tradicional" ${ }^{43}$.

Não obstante o motor da mudança na região ser exógeno e os centros urbanos, seus principais irradiadores, a intervenção governamental não seria capaz, por si só, de romper a inércia cultural. É neste ponto que Pierson defende a centralidade da pesquisa socioantropológica. Ao conferir inteligibilidade ao "impacto da mudança vinda de fora" (Pierson, 1972, III:461), ela poderia orientar os agentes da intervenção na superação das resistências da comunidade, conquistando-lhe a adesão. As ciências sociais se tornavam uma das forças a serviço da modernização.

\section{DONALD PIERSON E A "MUDANÇA SOCIAL PROVOCADA"}

O Projeto do São Francisco representa uma inflexão no pensamento de Pierson, que passa a articular rigor científico e comprometimento social, compartilhando assim o "otimismo sociológico" vigente nos anos 1950, da crença dos efeitos positivos do desenvolvimento sobre a sociedade brasileira, tais como a elevação dos padrões de vida e de consumo e a inserção de amplos setores do campo ao mundo dos direitos. 
É possível acompanhar tal mudança analisando-se investigações anteriores do sociólogo. No caso da pesquisa na comunidade rural de Cruz das Almas (nome fictício para Araçariguama, cidade do interior paulista), realizada entre 1946 e 1947, a ênfase de Pierson recaiu sobre a formação de sociólogos-pesquisadores e a divulgação da sociologia moderna no país. No prefácio à edição norte-americana do trabalho (1966 [1951]:xiv), ele destaca ainda o interesse científico que o Brasil despertava em função de sua diversidade cultural e extensão territorial.

Pierson buscou examinar as bases ecológicas e a vida sociocultural da comunidade, marcada pelo predomínio da pequena propriedade rural. Embora tenha analisado as mudanças estruturais ocorridas em seu interior, e que apontavam para a diminuição da distância entre as classes sociais, o sociólogo não relacionou o estudo à possibilidade de aplicação. Com efeito, nesse caso, um dos primeiros estudos de comunidade conduzidos no Brasil, estava em jogo a afirmação de um padrão de afazeres sociológicos calcado no trabalho de campo, conduzido por pessoal treinado, que buscava se contrapor à reflexão social considerada diletante, associada ao "ensaísmo" ${ }^{44}$.

Nesse momento, portanto, era importante diferenciar a função do cientista social em relação aos demais atores que se dedicavam ao estudo ou à intervenção na vida social, como o pensador social, o filósofo, o historiador, o moralista e o assistente social (ver Corrêa, 1987; Limongi, 1989; Oliveira, 1995; Lopes 2012). Em Teoria e Pesquisa em Sociologia (1962 [1945]), livro que reuniu suas aulas e palestras durante a primeira metade da década de 1940, Pierson se manifestou acerca da aplicação do conhecimento sociológico:

É pena, pois, que os sociólogos e outros cientistas sociais estejam atualmente sob a pressão de alguns governos, aliás, bem intencionados, para resolverem, desde já, seus problemas práticos. [...] Devemos [...] admitir francamente que ainda não estamos em condições de dar, de maneira certa, todos os conselhos que se desejam. A prova disto é que dezenas de esforços sinceros, inteligentes e bem intencionados, para tratar de problemas sociais, não só falharam, parcial ou completamente, mas também foram até agora impotentes para impedir o desenvolvimento, sempre para "pior", de cada um destes problemas. Como ciência, a nossa disciplina é ainda jovem e imatura (ibidem:45-46).

Pierson registra a demanda pela aplicabilidade do conhecimento na solução de problemas sociais, como os decorrentes do crescimento ur- 
bano, e afirma, em tom pessimista, que não cabia ao sociólogo o envolvimento direto com questões de natureza prática em função do estágio incipiente de institucionalização das ciências sociais. Neste ponto, Pierson se aproximava das concepções de ciência de sociólogos norte-americanos ligados à Universidade de Chicago, como William Thomas e Robert Park (Lopes, 2012).

Em contrapartida, os argumentos de Pierson acerca da relevância do Projeto do São Francisco indicam que sua perspectiva sofrera mudanças: afinado com as transformações econômico-sociais em curso nos anos 1950, ele confere maior importância à utilidade da pesquisa para governos e agências promotoras do desenvolvimento, para além dos efeitos positivos de tais projetos no processo de legitimação do modelo de análise social fundado na pesquisa empírica. A inflexão de Pierson se traduziu pela redefinição do papel do sociólogo, não mais pensado apenas como cientista-investigador, mas também como colaborador dos agentes da intervenção social, provendo dados e orientando-lhes a ação.

Em carta a Jaime Duarte, técnico em educação da CVSF, por ocasião das negociações envolvendo o financiamento das pesquisas no Vale, Pierson manifestou sua convicção acerca da "absoluta necessidade da realização de estudos prolongados e pormenorizados como fundamento para um eficaz planejamento social" ${ }^{\prime 4}$. Contudo, as atividades do pesquisador e do planejador social não deviam se confundir. Isto porque "[mudava-se] de tal forma [o] ponto de vista [do sociólogo] que não mais [podia] ele ter aquela objetividade e independência indispensáveis para a pesquisa realista e frutífera" (ibidem:1, ênfase nossa). Cioso da autonomia do cientista na determinação do escopo de investigação, Pierson ponderou que as pesquisas, embora financiadas pela CVSF, seriam realizadas "sob [sua] própria orientação e responsabilidade, abrangendo os problemas a serem estudados, os lugares mais indicados para as pesquisas futuras e tudo mais que a eles se relacionar". Quanto à colaboração, a equipe de pesquisadores sob sua direção "tudo [faria] para atender aos pedidos da [CVSF] no que diz respeito a orientações sobre planejamento. O nosso principal interesse, tomo a liberdade de frisar novamente, é o de estudar a vida social das populações [da região]" (ibidem:2).

Tais considerações normativas sobre o comportamento do sociólogo aproximam-se de concepções mertonianas acerca dos valores e senti- 
mentos que constituiriam o ethos científico. Socializados no universo da ciência, os cientistas estariam atentos à ingerência de critérios extracientíficos na produção de conhecimento (Merton, 1973). Por outro lado, Pierson argumentava pragmaticamente a favor da compatibilização entre as dimensões básica e aplicada da sociologia. A pesquisa seria "frutífera" na medida em que o cientista conseguisse, durante sua realização, desembaraçar-se dos imperativos práticos em jogo ${ }^{46}$.

Distante da figura do intelectual público ou militante, a exemplo de ex-alunos como Darcy Ribeiro (Bomeny, 2001:188), e mesmo de uma sociologia de intervenção de feição mannheimiana, ao modo de Guerreiro $\operatorname{Ramos}^{47}$ (Werneck Vianna, 1997), Pierson assume a postura de um sociólogo pragmático, que pretende se manter nos "limites do rigorosamente observável, preservando o sentido realista da aplicabilidade do conhecimento científico do social" (Vila Nova, 1998:142). Trata-se de um sociólogo que, não tomando para si a tarefa de formular amplos projetos de transformação, aposta em mudanças graduais na ordem social, nos estreitos marcos institucionais da democracia liberal e longe de qualquer "procedimento radical" de intervenção, visto como sinônimo de totalitarismo (Pierson et alii, 1952:30).

As tensões presentes no perfil de Pierson - como sociólogo que ora investe na conciliação dos interesses das ciências básica e aplicada, ora se posiciona normativamente frente a modelos de intervenção social - fazem parte da nova condição do sociólogo na era dos grandes projetos coletivos dos anos 1950, sob o signo da "mudança social provocada", nas palavras de Emilio Willems (1943), marca de distinção do tempo dos sociólogos. Esta expressão-síntese, como bem analisa Villas Bôas (2006:13), "revelava a liberdade de agir dentro de um plano elaborado de antemão. Traduzia o desejo de intervir na espontaneidade dos acontecimentos para mudar a feição das instituições, das mentalidades, da distribuição de poder, impondo regularidade nova à conduta cotidiana de homens e mulheres".

O Projeto do São Francisco é representativo da convergência entre o processo de afirmação das ciências sociais como referencial investigativo e explicativo da sociedade brasileira e a agenda desenvolvimentista da década de 1950. Neste contexto, Pierson empenhou-se na tradução de demandas sociais em desafios científicos que, por sua vez, viabilizariam as mudanças julgadas necessárias. 


\section{CONSIDERAÇÕES FINAIS}

Este texto analisou as relações entre ciências sociais e desenvolvimento a partir do Programa de Pesquisas do Vale do Rio São Francisco. As investigações tiveram lugar durante o segundo Governo Vargas, período em que debates sobre desenvolvimento, planejamento, mudança provocada e resistências à mudança tornaram-se obrigatórios. A descrição minuciosa da ecologia e da vida social do Vale do São Francisco associava-se a um programa de desenvolvimento regional patrocinado pela CVSF. Os vínculos entre produção de conhecimento e projetos de modernização são um indicador da estreita cooperação entre cientistas sociais e administradores na "era do desenvolvimento".

Na parte final da trilogia O Homem do Vale do São Francisco, há um apêndice intitulado "Algumas Sugestões sobre o Planejamento Social". Pierson demonstra certa cautela ao abordar o papel do sociólogo, sobretudo quando procura trazer soluções para os problemas existentes na região do Vale, declarando que não caberia ao cientista social definir normas para a sociedade. Ele não deixa de ponderar, contudo, que "talvez fosse útil sugerir [...] algumas 'diretrizes' para o planejamento social em geral" (Pierson, 1972, III:471).

Pierson apresenta, então, um extenso catálogo de sugestões na esfera da engenharia social, conjunto de iniciativas geralmente estatais que pretendem mudar atitudes e comportamentos da sociedade. A seu ver, a "introdução deliberada da mudança social" era de difícil consecução devido à força da tradição (ibidem:472-473). O sociólogo chama a atenção para a dimensão humana implicada no processo de intervenção social, afirmando a necessidade de "conhecer bem as pessoas que se procura ajudar, e entender-lhes os desejos, esperanças, aspirações e motivação, bem como a disposição, e a capacidade, de granjear-lhes não somente o apoio, mas também a ajuda ativa ao novo projeto" (idem:473). O "Projeto do Vale" estava em sintonia com uma vertente pragmática dos chamados estudos de comunidade, que concebiam estas investigações como uma contribuição ao "conhecimento mais aprofundado e mais minucioso da realidade nacional, permit[indo] uma eficiência maior ao trabalho de todos aqueles técnicos que, pelo caráter de suas atividades, são, ao mesmo tempo, agentes de mudança social e cultural: o agrônomo, o médico, especialmente o sanitarista, o educador e outros" (Nogueira, 1955:98). 
Contudo, as pesquisas do Vale foram além. A inflexão de Pierson se aproxima de uma série de propostas identificadas com o denominado "desenvolvimento/organização de comunidade". O conceito de "desenvolvimento de comunidade" tem sua origem na tradição anglo-saxã do entreguerras, e se desdobra no pós-Segunda Guerra na implementação do Ponto IV. Trata-se de uma modalidade de intervenção social baseada no trabalho de organização dos indivíduos em programas de combate ao analfabetismo, de melhoria das condições de saúde, modernização da agricultura, abastecimento d'água etc. Estas ações em comunidades, realizadas por agências locais, nacionais e internacionais, deveriam respeitar as especificidades culturais de suas populações e principais lideranças, criando condições para o êxito das mudanças almejadas (Campos, 2006; Maio e Lopes, 2012).

Ao analisar o envolvimento do cientista social em projetos de planejamento social, Pierson inspirou-se na experiência de um grupo de professores e alunos de um curso de Pós-Graduação em Saúde Pública da Universidade de Berkeley. Parte significativa dos participantes do curso tinha experiência de pesquisa, administração ou magistério em saúde pública em vários países, incluindo Brasil, Chile, Peru, México, El Salvador, Irã, Índia, Ceilão, China e Estados Unidos. O coordenador do curso foi o antropólogo George Foster, ex-diretor do ISA, e mais tarde, colaborador, durante vários anos, na avaliação de programas de saúde pública da Organização Mundial de Saúde (OMS), especialmente na América Latina.

O grupo reuniu-se ao longo de 12 semanas com o objetivo de analisar a eficácia do planejamento social. O resultado foi a elaboração de uma série de sugestões que norteariam a introdução de programas envolvendo alterações do quadro social. Em princípio, destacou-se a necessidade de estudo minucioso da comunidade antes do desenvolvimento do programa. Quanto às medidas de ordem prática destinadas à implementação de projetos visando à "mudança social orientada", caberia: 1) Conhecer a cultura na qual será introduzida a mudança; 2) Aferir as potencialidades da comunidade-alvo com base em conhecimento pragmático da realidade; 3) Iniciar o planejamento social com ações tópicas, moleculares, com resultados viáveis a curto prazo; 4) Definir um programa em que as partes se complementem, procurando não correr o risco de fragmentação, de iniciativas isoladas; 5) Escolher cuidadosamente a comunidade a ser objeto da mudança; 6) Estar atento à seleção 
das pessoas que estarão liderando o processo de mudança; 7) Valer-se da "natureza pragmática" de todo indivíduo, mobilizando os habitantes da comunidade a partir dos próprios fins práticos que perseguem; 8) Contar sempre que possível com a liderança local; 9) Não medir esforços para impedir que membros da comunidade se oponham ao projeto (Pierson, 1972, III:474-475).

A lista de sugestões do "grupo de Berkeley" teve por base as experiências malsucedidas resultantes de tensões, conflitos, resistências culturais de populações rurais à medicina científica ocidental. O Brasil e outros países haviam acumulado fracassos por falta de conhecimento e reconhecimento das práticas terapêuticas tradicionais e das formas locais de organização comunitária, o que gerava dificuldades na relação entre dirigentes, equipes e comunidades (Foster et alii, 1951; Paul, 1955). O Sesp colecionou alguns insucessos, como o experimento social do pequeno município mineiro de Chonin de Cima, relatada pelo antropólogo do Sesp e da ELSP Kalervo Oberg no início dos anos $1950^{48}$, ou no caso de Aimorés, no Espírito Santo (Fontenelle, 1959). No mesmo período, coletâneas foram publicadas nos EUA analisando experiências em África, Ásia e América Latina (Paul, 1955).

Ao lançar mão de sugestões para o desenvolvimento/organização de comunidades, que enfatiza o envolvimento da população local no processo de mudança, Pierson buscava contrapor-se às ações em planejamento vinculadas aos "sistemas totalitários", a exemplo da experiência nazista na Segunda Guerra (Pierson, 1972, III:471). No contexto de Guerra Fria, Pierson foi categórico ao afirmar que as soluções de cunho autoritário aos problemas sociais, violentamente impostas como as únicas possíveis, não deviam ser "toleradas por povos que vivem segundo princípios democráticos" (ibidem:472). Ademais, em face da "tenacidade da tradição", a "força nos assuntos humanos" tinha efeitos passageiros (idem). Isto é, o valor do desenvolvimento/organização de comunidades em termos de sua eficácia era indissociável das virtudes políticas que deveriam inspirá-lo: o pluralismo e a participação associados às democracias ocidentais. Deste modo, Pierson revela seu compromisso não apenas com a mudança social no país, mas também com os caminhos políticos que deveriam efetivá-la.

O exame do Projeto do Vale do São Francisco permitiu abordar as relações entre ciências sociais e desenvolvimento no Brasil. Mantidas suas especificidades, a posição de Pierson neste momento, ao sublinhar a 
participação do sociólogo-pesquisador no processo de "mudança provocada", apresenta afinidades com a de outros cientistas sociais, tais como Oracy Nogueira, Emílio Willems, Luiz de Aguiar Costa Pinto, Florestan Fernandes e Guerreiro Ramos. Na era do desenvolvimento, esses profissionais não perderam de vista a possibilidade de instrumentalizar o conhecimento socioantropológico a favor das mudanças em curso.

(Recebido para publicação em setembro de 2012) (Reapresentado em fevereiro de 2013) (Aprovado para publicação em abril de 2013) 


\section{NOTAS}

1. O emprego do termo "estudos de comunidade" por vezes sugere uma homogeneidade inexistente entre as pesquisas realizadas (Guidi,1962). Ele engloba diferentes iniciativas que diferem em seus objetivos, técnicas de investigação e alcance analítico, compreendendo, dentre outros, trabalhos etnográficos, de organização de comunidade e de caráter histórico. Oscilam entre a concepção da pesquisa de comunidade como método e como objeto de estudo.

2. Para uma apreciação da fortuna crítica sobre os estudos de comunidade, ver Oliveira (2010); Jackson (2009); Peixoto e Simões (2003); Consorte (1996).

3. Analisando pesquisas de Emílio Willems, Lima (1999:177) observa que o escopo da proposta dos estudos de comunidade era maior do que sugere a crítica de Guerreiro Ramos, uma vez que eles "aspiravam constituir-se em bases de pedagogia de transformação do caboclo, do imigrante 'acaboclado' e de outros atores sociais, de ruptura com o multissecular processo de transmissão cultural".

4. Pierson promoveu, ainda, o contato entre indivíduos de diferentes regiões do país, no esforço de criar uma rede de interessados na investigação sociológica, além de ter desempenhado papel central na concessão de bolsas de estudo para alunos brasileiros nos Estados Unidos. Ver Pierson (1987).

5. O livro de Pierson foi precedido por uma série de estudos levados a cabo por pesquisadores da ELSP sob sua orientação no âmbito do "Projeto do Vale": Medicina Rústica, publicado em 1959, e Populações Ribeirinhas do Baixo São Francisco, publicado em 1961, ambos de Alceu Maynard Araújo; Potengi: Encruzilhada no Vale do São Francisco, de Alfonso Trujillo Ferrari (1960); Cerrado e Retiro: Cidade e Fazenda no Alto São Francisco, de Esdras Borges Costa (1960); Xique-Xique e Marrecas: Duas Comunidades do Médio São Francisco, de Fernando Altenfelder Silva (1961); e Análise Comparativa de Alguns Aspectos da Estrutura Social de duas Comunidades do Vale do São Francisco, apresentada por Altenfelder como tese de Livre-Docência junto à Faculdade de Filosofia, Ciências e Letras da Universidade do Paraná em 1955; e outros dois estudos que não chegaram a ser publicados: Rio Rico e os Gerais: Estudo de Dois Grupos Humanos no Platô Ocidental do Vale do São Francisco, de Levy Cruz; e o estudo de Cabrobó, coordenado por Octavio da Costa Eduardo.

6. Em carta a George Foster, Pierson fornece importante indício de que já havia vislumbrado a possibilidade de pesquisas sobre mudança social e cultural com base no interesse do governo brasileiro em projetos de desenvolvimento nas regiões do Vale do Rio São Francisco e do Vale do Rio Doce e na construção da usina siderúrgica de Volta Redonda. Carta de Pierson a George Foster, 21/9/1948, p. 3. Records of Institute of Social Anthropology Smithsonian Institution 1942-1952, National Anthropological Archives, Series 4 Correspondence, Pierson, Donald, 1948-49, Box 10.

7. O Departamento de Sociologia e Antropologia da Universidade de Chicago, fundado em 1892, deu origem a uma tradição de investigação empírica em resposta aos inúmeros problemas sociais decorrentes do boom demográfico e do acelerado desenvolvimento urbano-industrial vivido por Chicago a partir do final do século XIX, tais como a tensão interétnica (envolvendo principalmente imigrantes europeus e negros vindos do Sul), o divórcio e a delinquência juvenil. Ver Coulon (1995); Chapoulie (2001) e Valladares (2005). 
8. Para análises da atuação de Julian Steward e do funcionamento do ISA, ver Castro (2010); Price (2008) e Figueiredo (2009).

9. Formado em Economia na Universidade da Columbia Britânica (Canadá), em 1928, Oberg ingressou no Programa de Antropologia da Universidade de Chicago em 1930. Foi um dos primeiros antropólogos a fazer parte do programa do Instituto de Assuntos Interamericanos (IAIA), destinado à América Latina. Lecionou na ELSP por seis anos (1946-1952) e atuou como "social science consultant" no Serviço Especial de Saúde Pública (McComb e Foster, 1974:357-358); Falhauber (2001).

10. "A Preliminary Survey of the Valley of São Francisco", 1949. Fundo Donald Pierson, pasta 72. AEL. Tradução livre.

11. Considerando-se as incertezas sobre a continuação do apoio do ISA a pesquisas no Brasil nesse período, em decorrência das mudanças na política externa norte-americana com o fim da Segunda Guerra Mundial, pode-se inferir que Pierson procurou mostrar ao ISA a relevância do conhecimento que o governo norte-americano estava ajudando a produzir e, assim, garantir a manutenção do financiamento de suas atividades no Brasil (Figueiredo, 2009).

12. Sobre o processo de institucionalização das Ciências Sociais no Brasil, ver Corrêa (1987); Miceli (1989); Limongi (1989); Massi (1989) e Oliveira (1995).

13. Bielschowsky (1995) aborda os vínculos entre planejamento e industrialização no pensamento de economistas brasileiros como Roberto Simonsen. O autor também destaca a repercussão dos diagnósticos da Comissão Econômica para a América Latina (CEPAL) nos usos que se fizeram, no Brasil, da noção de planejamento no campo econômico.

14. BRASIL. Constituição dos Estados Unidos do Brasil de 18 de setembro de 1946. Disponível em http://www.planalto.gov.br/ccivil_03/constituicao/constitui\%C3\% A7ao46.htm. Acesso em 2/9/2012.

15. BRASIL. Lei no 541 de 15 de dezembro de 1948. Cria a Comissão do Vale do São Francisco e dá outras providências. Disponível em http:/ / www.codevasf.gov.br/principal/legislacao/leis/lei-nb0-541-de-15-de-dezembro-de-1948. Acesso em 1/7/2010.

16. Sobre a importância econômica do Vale nesse período, ver Andrade (2006); Vainer (2007); Camelo Filho (2005, 2008); Coelho Neto (2009).

17. Lucas Lopes (1911-1994) teve papel de destaque nas políticas de expansão energética na década de 1950. Integrou a Comissão de Administração do Banco Nacional de Desenvolvimento Econômico (BNDE) em 1952, trabalhando também no Conselho de Desenvolvimento (órgão de aplicação do Plano de Metas do Governo Juscelino Kubitscheck). Centro de Pesquisa e Documentação de História Contemporânea do Brasil da Fundação Getulio Vargas. Disponível em http://cpdoc.fgv.br/producao/dossies/biografias/lucas_lopes. Acesso em 17/8/10.

18. Os autores que, a exemplo de Escobar (1996), buscaram compreender o desenvolvimento como um fenômeno cultural fazem parte dos denominados post-development studies. Para uma discussão em torno dessa abordagem, ver Andrade (2012).

19. Public Papers of the Presidents. Harry S. Truman. January 20, 1949. Harry S. Truman Library and Museum. Disponível em http://www.trumanlibrary.org/publicpapers. Acesso em 20/8/2012. 
20. "A Preliminary Survey of the Valley of the São Francisco", 1949. Fundo Donald Pierson, pasta 72, AEL; Carta de Donald Pierson a Paulo Peltier de Queiroz em 3 de janeiro de 1952. Fundo Donald Pierson, pasta 57, AEL.

21. "As pesquisas levadas a efeito no Vale do São Francisco - 28.02.1959". Fundo Donald Pierson, Pasta 56, AEL.

22. Os gastos da CVSF com o "Projeto do Vale" como um todo foram de Cr $\$ 490.000,00$ (quatrocentos e noventa mil cruzeiros), o equivalente a 62 mil reais em números de 25/4/2010. Valor calculado com base no Índice Geral de Preços. Disponível em: www.calculoexato.com.br.

23. Os pares foram: 1을 Cerrado e Retiro (2.825 habitantes), em Minas Gerais; $2 \underline{0}$ : Correntina e Gerais (19.306 hab.), na Bahia; 3ㅇ: Xique-Xique e Marrecas (33.004 hab.), também na Bahia; 4으: Cabrobó e Ilha de Toré (10.235 hab.), em Pernambuco; 5으: Piaçabuçu e Potengi (9.500 hab.), em Alagoas. Nessas localidades, 69,7\% da população vivia em áreas rurais (Pierson, 1972, II:15).

24. "The São Francisco Project - 28/2/1959". Fundo Donald Pierson, Pasta 56, AEL.

25. Carta de Donald Pierson a Paulo Peltier de Queiroz em 10.08.1950. Fundo Donald Pierson, Pasta 57, AEL.

26. Sobre os estudos de ecologia humana desenvolvidos por Park e Burgess, ver Eufrásio (1999). Análises sobre os temas e objetos privilegiados pelos sociólogos de Chicago encontram-se em Coulon (1995) e Chapoulie (2001).

27. A obra foi publicada no Brasil em 1949 como parte da coleção organizada por Pierson, denominada "Biblioteca de Ciências Sociais" (Pierson, 1987:52-54). Ao lado de Robert Park e Louis Wirth, Redfield foi um dos orientadores de Pierson em sua pesquisa de doutoramento sobre as relações raciais na Bahia (ibidem:34).

28. Comunicação do Departamento de Produção e Assistência da CVSF ao presidente da República, s/d. Fundo Donald Pierson, pasta 57, AEL.

29. Comunicação do Departamento de Produção e Assistência da CVSF ao presidente da República, s/d. Fundo Donald Pierson, pasta 57, AEL.

30. Unesco Courier, vol. 1, n- 3, abril de 1948, p. 4.

31. A região era marcada não só pelo elevado índice de analfabetismo, como também pelo predomínio de doenças tropicais, desmatamento e agricultura pouco produtiva.

32. Pierson fez uma nova viagem ao Vale do São Francisco patrocinada pela Fundação Rockefeller, em 1959. Ela teve como objetivo permitir ao sociólogo fazer uma revisão das informações e análises do manuscrito entregue à CVSF no mesmo ano (Pierson, 1972, I:20). No entanto, o livro só foi publicado 13 anos depois. Houve mudanças administrativas na CVSF, que em 1967 tornara-se Superintendência do Vale do São Francisco (Suvale), além de dificuldades no financiamento da tradução e na publicação da obra, que chegou a ter capítulos desaparecidos nos gabinetes do órgão (Oliveira, 2010).

33. As consequências da interação desses grupos são entrevistas no estabelecimento de uma ordem política com base na distribuição fundiária, na construção de habitações segundo o estilo europeu e na adoção de práticas religiosas de origem africana (Pierson, 1972, I:248-249). 
34. A população estava distribuída de forma irregular pela região, concentrando-se nas grandes fazendas ou em pequenas cidades e vilarejos. Nos cinco pares de localidades estudados, o número de homens e mulheres era relativamente semelhante, com predomínio da população jovem (Pierson, 1971, II:18-24). Em todas as comunidades estudadas a população era miscigenada, embora a predominância de brancos, negros ou indígenas variasse conforme diferentes circunstâncias históricas, tais como povoamento e migração. Nas duas extremidades do Vale, onde o povoamento ocorrera em função das minas de ouro e dos engenhos de cana-de-açúcar, era maior o número de negros, enquanto nas áreas mais isoladas havia maior concentração de indígenas (ibidem:24-28).

35. A construção da Represa de Três Marias, visando ao controle das inundações periódicas do rio, e a exploração de petróleo em torno de sua foz também abriam novas perspectivas econômicas (Pierson, 1972, III: 460).

36. O Sesp atuou nos estados da Paraíba, Pernambuco e Bahia em áreas econômicas estratégicas e no treinamento de profissionais de saúde. No primeiro semestre de 1950 assinou um convênio com a CVSF (Campos, 2006:211-212).

37. Além da malária, verminoses, doenças venéreas, disenteria, tifoide e paratifoide, leishmaniose e doença de Chagas eram as principais doenças diagnosticadas no Vale. Em Correntina havia ocorrido, em 1940 e 1941, uma séria epidemia de paratifoide que afetou mais de uma centena de pessoas, na ocasião sem qualquer assistência médica (Pierson, 1972, III:161-162, 263-264).

38. Cientistas sociais vinculados à Divisão de Educação Sanitária do Sesp, a exemplo de José Arthur Rios e Luiz Fernando Raposo Fontenelle, detiveram-se no estudo do universo cultural das populações-alvo das políticas de saúde na zona rural. Ambos assinalaram a hostilidade e a incompreensão que por vezes caracterizavam a relação entre pacientes e profissionais de saúde, decorrentes do choque cultural (Maio e Lima, 2009).

39. Pierson critica as condições precárias de ensino no Vale, ainda que indique as ações do poder público no setor. Em localidades como Cerrado, a porcentagem de pessoas alfabetizadas chegava apenas a 30\% (Pierson, 1972, III:343-344).

40. Pierson afirma que parecia ser maior a aceitação da escola, do professor e do processo de aprendizagem em cidades cujo contato com os centros metropolitanos era mais estreito, entre membros da elite local e entre famílias protestantes (Pierson, 1972, III:335).

41. Cepêda (2012) observa que a perspectiva desenvolvimentista do período enfatizava a mudança nas atividades produtivas, restringindo-se por vezes à esfera econômica, à criação, nos países periféricos, de um robusto mercado interno, diversificado e autônomo.

42. Algumas características presentes na concepção de Pierson sobre o moderno - tais como diferenciação socioeconômica, adoção de valores políticos democráticos e mentalidade secularizada, ligada à racionalidade científica - lembram não apenas visões sociológicas clássicas sobre a história ocidental, como também foram exploradas ao longo dos anos 1950 e 1960 pela sociologia da modernização de matriz norte-americana, cuja base teórica provinha do estrutural-funcionalismo parsoniano (Sztompka, 2005:232-233). No contexto latino-americano, a teoria da modernização 
foi interpelada e reinterpretada por Florestan Fernandes e Gino Germani, que buscaram conferir-lhe densidade histórica (Brasil Júnior, 2011).

43. Para uma análise da contribuição de sociólogos brasileiros na compreensão da coexistência tensa e dos arranjos complexos entre modernidade e tradição no processo de transformação social do país, ver Villas Bôas (2006).

44. O "ensaísmo" é geralmente visto como produção intelectual pré-científica, vinculado a autores como Oliveira Vianna, Sergio Buarque de Holanda e Caio Prado Junior, intérpretes da formação sócio-histórica do país. Como observa Botelho (2010), a despeito das semelhanças, os ensaios não podem, contudo, ser igualmente subsumidos a um mesmo conjunto de "características cognitivas ou narrativas exclusivas" - unidade esta que "se colocou a posteriori, e em especial pelas ciências sociais". Os primeiros balanços e interpretações sobre a história das ciências sociais no país produzidos nos anos 1940 e 1950 tenderam a reafirmar a cientificidade das investigações sociais no novo contexto de institucionalização universitária, contrastando-a ao caráter "pré-científico" da produção intelectual até então existente. Para um exame crítico do marco institucionalista na história das ciências sociais, ver Santos (1978), Oliveira (1995) e Lima (1998).

45. Carta de Donald Pierson a Jaime Duarte em 13. 04. 1950. Fundo Donald Pierson, Pasta 63. AEL. p. 1.

46. Certamente Pierson se preocupou com o fato de que as pesquisas no Vale, além dos usos práticos, alcançassem reconhecimento em termos de seu valor científico. Nos Estados Unidos, a crescente demanda social por conhecimento socioantropológico a partir da instauração do Ponto IV foi vista pelos cientistas sociais do ISA como oportunidade de expansão do escopo de sua disciplina e demonstração do valor prático do saber socioantropológico (Figueiredo, 2009). No entanto, à semelhança do caso de Pierson, a aproximação com um modelo de ciências sociais aplicadas acabou por tensionar as normas do ethos científico, trazendo para o plano das considerações dos cientistas critérios de natureza política.

47. Nos anos 1950, Guerreiro Ramos se posicionou a favor do comprometimento normativo explícito do cientista social com a tarefa de construção da nação. Tratava-se da confluência das atividades de pesquisa e teorização sociológicas com os desafios práticos e políticos do desenvolvimento socioeconômico. Ver, a este respeito, Werneck Vianna (1997); Maio e Lopes (2012).

48. O Sesp havia estabelecido, no início de 1951, em Chonin, programas de saúde, agricultura e educação, nos quais a população participaria por meio de um Conselho de Comunidade. Ao analisar o fracasso dos programas, Oberg (1961:44-48) relatou um incidente, numa festa patrocinada pelos funcionários do projeto, em que a disputa política entre os líderes locais culminou com o encerramento das atividades do projeto do Sesp. O episódio revelou que o programa estava em "dissonância com os valores, as personalidades e a estrutura tradicionais da comunidade", aspectos apontados pelo antropólogo como essenciais para a continuidade dos trabalhos. 


\section{REFERÊNCIAS BIBLIOGRÁFICAS}

AMRITH, Sunil e SLUGA, Glenda. (2008), "New Histories of the United Nations". Journal of World History, vol. 19, no 3, pp. 251-274.

ANDRADE, Renata M. T. (2006), The "Third Bank" of the Lower São Francisco River: Culture, Nature and Power in the Northeast Brazil 1853-2003. Tese de Doutorado em Filosofia, Berkeley, University of California.

ANDRADE, Rômulo de Paula. (2012), A Amazônia na Era do Desenvolvimento: Saúde, Alimentação e Meio Ambiente (1946-1966). Tese de Doutorado em História das Ciências e da Saúde, Rio de Janeiro, Fundação Oswaldo Cruz/Casa de Oswaldo Cruz.

ANUÁRIO DA ESCOLA LIVRE DE SOCIOLOGIA E POLÍTICA. (1947), São Paulo, Escola Livre de Sociologia e Política.

BIELCHOWSKY, Ricardo. (1995), Pensamento Econômico Brasileiro: O Ciclo Ideológico do Desenvolvimentismo. 2a ed. Rio de Janeiro, Contraponto.

BOMENY, Helena. (2001), Darcy Ribeiro: Sociologia de um Indisciplinado. Belo Horizonte, Ed. UFMG.

BOTELHO, André. (2010), “Passado e Futuro das Interpretações do País”. Tempo Social, vol. 22, no 1 , pp. 47-66.

BRASIL JUNIOR, Antonio da Silveira. (2011), Passagens para a Teoria Sociológica: Florestan Fernandes e Gino Germani. Tese de Doutorado em Sociologia, Rio de Janeiro, IFCS/UFRJ.

CAMELO FILHO, José Vieira. (2005), “A Dinâmica Política, Econômica e Social do Rio São Francisco e do seu Vale". Revista do Departamento de Geografia da USP, no 17, pp. 83-93.

(2008), “A Política Econômica Regional do Vale do São Francisco: Uma Busca do Desenvolvimento do Interior Brasileiro". Revista de Estudos Sociais, Ano 10, vol. 2, no 20, pp. 67-87.

CAMPOS, André Luiz V. de. (2006), Políticas Internacionais de Saúde na Era Vargas: O Serviço Especial de Saúde Pública, 1942-1960. Rio de Janeiro, Editora Fiocruz.

CASTRO, A. Peter. (2010), “Collaborative Researchers or Cold Warriors? The Origins, Activities, and Legacy of the Smithsonian's Institute of Social Anthropology". Journal of Global and International Studies, vol. 2, no 1, pp. 56-82.

CEPÊDA, Vera Alves. (2012), “Inclusão, Democracia e Novo-Desenvolvimentismo: Um Balanço Histórico". Estudos Avançados, vol. 26, no 75, pp. 77-90.

CHAPOULIE, Jean Michel. (2001), La Tradition Sociologique de Chicago (1892-1961). Paris, Éditions du Seuil.

COELHO NETO, Agripino Souza. (2009), Trajetórias e Direcionamentos da Política de Irrigação no Brasil: As Especificidades da Região Nordeste e do Vale do São Francisco. Trabalho apresentado no XIX Encontro Nacional de Geografia Agrária, São Paulo, 2-7 de fevereiro, pp. 1-32. 
CONSORTE, Josildeth Gomes. (1996), "Os Estudos de Comunidade no Brasil: Uma Viagem no Tempo", in M. Faleiros e R. Crespo (orgs.), Humanismo e Compromisso: Ensaios sobre Octavio Ianni. São Paulo, Editora da Unesp, pp. 51-68.

CORRÊA, Mariza. (1987), Histórias da Antropologia no Brasil: 1930-1960, Testemunhos: Donald Pierson e Emilio Willems. São Paulo/Campinas, Vértice/Editora Revista dos Tribunais/Ed. da Unicamp.

COSTA LIMA, Marcos. (2011), Região \& Desenvolvimento no Capitalismo Contemporâneo. Uma Interpretação Crítica. São Paulo, Cultura Acadêmica Editora.

COSTA PINTO, Luiz de Aguiar. (1950), "Pesquisas sobre a Bahia". A Tarde, Salvador, 27 de outubro, p. 3.

. (1953), O Negro no Rio de Janeiro: Relações de Raças numa Sociedade em Mudança. São Paulo, Companhia Editora Nacional.

COUlON, Alain. (1995), A Escola de Chicago. São Paulo, Papirus.

CUETO, Marcos. (2007), Cold War, Deadly Fevers: Malaria Eradication in México, 1955-1975. Baltimore, The Johns Hopkins University Press.

D'ARAÚJO, Maria Celina. (1992), “Amazônia e Desenvolvimento à Luz das Políticas Governamentais: A Experiência dos Anos 50". Revista Brasileira de Ciências Sociais, Ano 7, no 19, pp. 40-55.

ESCOBAR, Arturo. (1996), La Invención del Tercer Mundo. Construcción y Deconstrucción del Desarollo. Tradução de Diana Ochoa. Santa Fe de Bogotá, Editorial Norma.

EUFRÁSIO, Mário. (1999), Estrutura Urbana e Ecologia Humana: A Escola Sociológica de Chicago (1915-1940). São Paulo, PPGS-USP/Ed. 34.

FAULHABER, Priscila. (2011), “O Instituto de Antropologia Social (EUA, Brasil e México): Um Artefato da Resposta Antropológica ao 'Esforço de Guerra'”. Mana, vol. 17, no 1 , pp. 9-39.

FERNANDES, Florestan. (1958), A Etnologia e a Sociologia no Brasil. São Paulo, Ed. Anhembi.

. (1979), Mudanças Sociais no Brasil. (3a ed.). São Paulo, Difel.

FIGUEIREDO, Regina Érika Domingos de. (2009), Histórias de uma Antropologia da "Boa Vizinhança": um Estudo sobre o Papel dos Antropólogos nos Programas Interamericanos de Assistência Técnica e Saúde no Brasil e no México (1942-1960). Tese de Doutorado em Antropologia Social. Campinas, SP, Unicamp.

FONTENELLE, Luiz Fernando R. (1959), Aimorés. Análise Antropológica de um Programa de Saúde. Rio de Janeiro, DASP Serviço de Documentação.

FOSTER, George M. et alii. (1951), A Cross-Cultural Anthropological Analysis of a Technical Aid Program. Washington, D.C., Smithsonian Institution.

. (1979) [1967], “The Institute of Social Anthropology”, in G. M. Foster et alii (orgs.), The Uses of Anthropology. Washington, D.C., American Anthropological Association, pp. 205-216.

GUERREIRO RAMOS, Alberto. (1995) [1957], Introdução Crítica à Sociologia Brasileira. Rio de Janeiro, Ed. UFRJ.

DADOS - Revista de Ciências Sociais, Rio de Janeiro, vol. 56, nำ2, 2013 
GUIDI, Maria Laís M. (1962), “Elementos de Análise dos 'Estudos de Comunidades' Realizados no Brasil e Publicados de 1948 a 1960". Educação e Ciências Sociais, vol. 10, no 19, pp. 45-87.

HOCHMAN, Gilberto. (2009), “'O Brasil Não é Só Doença': O Programa de Saúde Pública de Juscelino Kubitschek". História, Ciências, Saúde-Manguinhos, vol. 16 (suplemento). Disponível em <http://www.scielo.br/scielo.php?script=sci_arttext\&pid= S0104-59702009000500015>. Acesso em 9/10/2013.

HOLANDA, Sérgio Buarque de (1979 [1948]). “Tradição e Transição I, II e III”, in Tentativas de Mitologia. São Paulo, Perspectiva, pp. 125-140.

JACKSON, Luiz. (2009), "Divergências Teóricas, Divergências Políticas: A Crítica da USP aos 'Estudos de Comunidades'". Cadernos de Campo, no 18, pp. 273-280.

LIMA, Nísia Trindade. (1999), Um Sertão Chamado Brasil: Intelectuais e Representação Geográfica da Identidade Nacional. Rio de Janeiro, Iuperj/Ed. Revan.

LIMONGI, Fernando. (1989), "A Escola Livre de Sociologia e Política em São Paulo", in S. Miceli (org.), História das Ciências Sociais no Brasil. São Paulo, Vértice, pp. 217-233.

LLEYS, Collin. (2005), “The Rise and Fall of Development Theory”, in M. Edelman e A. Hauguerud (orgs.), The Anthropology of Development and Globalization: From Classical Political Economy to Contemporary Neoliberalism. Oxford, Blackwell Publishing.

LOPES, Lucas. (1955), O Vale do São Francisco. Rio de Janeiro, Ministério da Viação e Obras Públicas. Serviço de Documentação.

LOPES, Thiago da Costa. (2012), Sociologia e Puericultura no Pensamento de Guerreiro Ramos: Diálogos com a Escola de Chicago (1943-1948). Dissertação de Mestrado em História das Ciências e da Saúde. Rio de Janeiro, Fundação Oswaldo Cruz/Casa de Oswaldo Cruz.

MAIO, Marcos Chor. (1997), A História do Projeto Unesco: Estudos Raciais e Ciências Sociais no Brasil. Tese de Doutorado em Ciência Política, Rio de Janeiro, Iuperj.

. (2009), “Estudos de Comunidade e Relações Raciais: O Convênio Columbia University /Estado da Bahia/Unesco na Década de 1950". Cadernos de Campo-Revista dos Alunos de Pós-Graduação em Antropologia Social da USP, vol. 18, no 18, pp. 257-271.

e LIMA, Nísia Trindade. (2009), “Tradutores, Intérpretes ou Promotores de Mudança? Cientistas Sociais, Educação Sanitária Rural e Resistências Culturais (1940-1960)". Sociedade e Estado, vol. 24, no 2, pp. 529-561.

MAIO, Marcos Chor e LOPES, Thiago da Costa. (2012), “Da Escola de Chicago ao Nacional-Desenvolvimentismo: Saúde e Nação no Pensamento de Alberto Guerreiro Ramos (1940-1950)". Sociologias, vol. 14, no 30, pp. 290-329.

MAIO, Marcos Chor e OLIVEIRA, Nemuel da Silva. (2010), “O Projeto de Criação do Instituto Internacional da Hiléia Amazônica e as Ciências Sociais no Contexto do Desenvolvimento". Cadernos Adenauer X (2009). Amazônia e Desenvolvimento Sustentável, no 4, pp. 59-70.

MAIO, Marcos Chor e SÁ, Magali R. (2000), “Ciência na Periferia: A Unesco, a Proposta de Criação do Instituto Internacional da Hiléia Amazônica e as Origens do Inpa". História, Ciências, Saúde-Manguinhos, vol. 6 (suplemento), pp. 975-1017. 
MASSI, Fernanda. (1989), “Franceses e Norte-americanos nas Ciências Sociais Brasileiras (1930-1960)", in S. Miceli (org.), História das Ciências Sociais no Brasil. São Paulo, Vértice, pp. 410-460.

McCOMB, Marlin R. e FOSTER, George. (1974), “Kalervo Oberg, 1901-1973 (Obituary)”. American Anthropologist, New Series, vol. 76, no 2, pp. 357-360.

MELATTI, Julio Cezar. (1984) "A Antropologia no Brasil: Um Roteiro". BIB - Boletim Informativo e Bibliográfico de Ciências Sociais, no 17, pp. 1-92.

MERTON, Robert K. (1973), "Science and the Social Order", in The Sociology of Science. Theoretical and Empirical Investigations. Chicago/London, The University of Chicago Press, pp. 254-266.

MÉTRAUX, Alfred. (1948), "Fundamental Education: Basic (Sociological) Surveys in Fundamental Education". Unesco Educ/63. Disponível em http://unesdoc.unesco.org/images/0012/001259/125908eb.pdf. Acesso em 21/9/12.

MICELI, Sérgio (org.). (1989), História das Ciências Sociais no Brasil. São Paulo, Vértice.

NOGUEIRA, Oracy. (1955), “Os Estudos de Comunidades no Brasil”. Revista de Antropologia, vol. 3, no 2, pp. 95-103.

OBERG, Kalervo. (1956), Chonin de Cima. A Rural Community in Minas Gerais, Brazil. Rio de Janeiro, USOM.

. (1961), "Interesses da Comunidade e Programas de Desenvolvimento Rural". Anais do Seminário Nacional sobre as Ciências Sociais e o Desenvolvimento de Comunidade Rural no Brasil. Rio de Janeiro, Ed. SSR, pp. 43-52.

OLIVEIRA, Lucia Lippi. (1995), A Sociologia do Guerreiro. Rio de Janeiro, Ed. UFRJ.

OLIVEIRA, Nemuel da Silva. (2010), Estudos de Comunidade, Ciências Sociais e Saúde: o Ciclo de Pesquisas no Vale do São Francisco na Década de 1950. Dissertação de Mestrado em História das Ciências e da Saúde, Fundação Oswaldo Cruz/Casa de Oswaldo Cruz.

e MAIO, Marcos Chor. (2012), “Ciências Sociais e Saúde no Ciclo de Pesquisas no Vale do São Francisco (1940-1950)”. Physis [online], vol. 22, no 2, pp. 733-753.

PACKARD, Randall. (1997), "Visions of the Postwar Health and Development and their Impact on Public Health Interventions in the Developing World", in F. Cooper e R. Packard (orgs.), International Development and the Social Sciences. Berkeley, University of California Press, pp. 93-118.

PAUL, Benjamin D. (1955), Health, Culture and Community. New York, Russel Sage Foundation.

PEIXOTO, Fernanda A. e SIMÕES, Júlio. (2003), "A Revista de Antropologia e as Ciências Sociais em São Paulo: Notas sobre uma Cena e Alguns Debates". Revista de Antropologia, vol. 46, no 2, pp. 383-409.

PIERSON, Donald. (1941), “Um Sistema de Referência para o Estudo dos Contatos Raciais e Culturais". Sociologia, vol. 3, no 1, pp. 1-17.

. (1962) [1945], Teoria e Pesquisa em Sociologia. 6ạ ed. São Paulo, Edições Melhoramentos.

(1966) [1951], Cruz das Almas. Rio de Janeiro, Livraria José Olympio Editora.

DADOS - Revista de Ciências Sociais, Rio de Janeiro, vol. 56, nำ 2, 2013 
. (1972), O Homem no Vale do São Francisco. Rio de Janeiro, Ministério do Interior/Suvale (três tomos).

(1987), "Depoimento", in M. Corrêa (org.), Histórias da Antropologia no Brasil: 1930-1960, Testemunhos: Donald Pierson e Emilio Willems. São Paulo/Campinas, Vértice/Editora Revista dos Tribunais /Editora da Universidade Estadual de Campinas.

PIERSON, Donald; COSTA EDUARDO, Octávio da e CRUZ, Levy. (1952), “Hipóteses e Sugestões sobre o Ensino no Vale do São Francisco". Revista Brasileira de Estudos Pedagógicos, vol. XVII, no 46, pp. 22-37.

PRADO JÚNIOR, Caio. (1948), “Métodos Sociológicos”. Fundamentos, no 7-8, pp. 23-30.

PRICE, David H. (2008), Anthropological Intelligence. The Deployment and Neglect of American Anthropology in the Second World War. Durham/London, Duke University Press.

REDFIELD, Robert. (1949), Civilização e Cultura de Folk: Estudo de Variações Culturais em Yucatan. São Paulo, Livraria Martins Fontes Ed.

RIOS, José Arthur. (1953) “Ciências Sociais e Saúde Pública”. Boletim do SESP, no 38, pp. 2-3.

RIST, Gilbert. (2002), The History of Development. From Western Origins to Global Faith. London/New York, Zed Books Ltd.

SANTOS, Wanderley Guilherme dos. (1978), "Paradigma e História: A Ordem Burguesa na Imaginação Social Brasileira", in Ordem Burguesa e Liberalismo Político. São Paulo, Duas Cidades, pp. 15-63.

SKIDMORE, Thomas E. (1976), Brasil: De Getúlio Vargas a Castelo Branco (1930-1964). 5a ed. Rio de Janeiro, Paz e Terra.

SORJ, Bila. (1999), "Demarcando o Campo da Sociologia: A Contribuição de Costa Pinto", in M. C. Maio e G. Villas Bôas (orgs.), Ideias de Modernidade e Sociologia no Brasil: Ensaios sobre Luiz Aguiar Costa Pinto. Porto Alegre, Ed. UFRGS, pp. 223-228.

SZTOMPKA, Piotr. (2005), A Sociologia da Mudança Social. 2a ed. Rio de Janeiro, Civilização Brasileira.

VAINER, Carlos B. (2007), “Fragmentação e Projeto Nacional: Desafios para o Planejamento Territorial", in C. C. Diniz (org.), Políticas de Desenvolvimento Regional: Desafios e Perspectivas à Luz das Experiências da União Europeia e do Brasil. Brasília, Ministério da Integração Nacional, pp. 103-124.

VALLADARES, Lícia do Prado. (2005), A Escola de Chicago: Impacto de uma Tradição no Brasil e na França. Belo Horizonte, Editora UFMG.

VILA NOVA, Sebastião. (1998), Donald Pierson e a Escola de Chicago na Sociologia Brasileira: Entre Humanistas e Messiânicos. Lisboa, Coleção Vega Universidade.

VILLAS BÔAS, Gláucia. (2006), Mudança Provocada: Passado e Futuro no Pensamento Sociológico Brasileiro. Rio de Janeiro, Editora FGV.

. (2007), A Vocação das Ciências Sociais no Brasil: Um Estudo da sua Produção em Livros do Acervo da Biblioteca Nacional, 1945-1966. Rio de Janeiro, Fundação Biblioteca Nacional.

WERNECK VIANNA, Luiz. (1997), A Revolução Passiva: Iberismo e Americanismo no Brasil. Rio de Janeiro, Revan. 
WAGLEY, Charles. (1951), “The Brazilian Amazon: The Case of Under-developed Area”. Four Papers presented in the Institute for Brazilian Studies. Nashville, Vanderbilt University Press, pp. 9-31.

WAGLEY, Charles e AZEVEDO, Thales de. (1951), “Sobre Métodos de Campo no Estudo de Comunidade". Revista do Museu Paulista, Nova Série, vol. V, pp. 227-237.

WAGLEY, Charles; AZEVEDO, Thales de e COSTA PINTO, Luiz A. (1950), Uma Pesquisa sobre a Vida Social no Estado da Bahia. Salvador, Publicações do Museu do Estado/Secretaria de Educação e Saúde, no 11, pp. 7-21.

WILLEMS, Emilio. (1943), “A Solução do Problema Rural Brasileiro como Mudança Social Provocada". Sociologia, vol. 2, no 5, pp. 20-28. 


\section{ABSTRACT \\ Donald Pierson and the São Francisco River Valley Project: Social Scientists in Action in the Age of Development}

Amid rapid social changes in Brazil in the 1950s, wide-reaching collective research projects in the social sciences were conducted in partnership between Brazilian and international agencies working in regional development. Cooperation between social scientists and government staff was based on the expectation that social and anthropological studies would orient the changes then under way. By approaching the research program in the São Francisco River Valley, the article examines a turning point in the career of sociologist Donald Pierson, combining analyses of context and content in his intellectual production. Pierson concentrated initially on the institutionalization of the social sciences in Brazil, promoting a standard of sociological work based on scientific research. In his research in the São Francisco River Valley, Pierson adopted a new approach by combining the sociologist's role as scientist with that of agent of social change, thereby highlighting the importance of the application of sociological knowledge in practice.

Key words: Donald Pierson; São Francisco River Valley Project; development; community studies; social change; history of the Social Sciences in Brazil

\section{RÉSUMÉ}

Donald Pierson et le Projet du Vale do Rio São Francisco: Spécialistes des Sciences Sociales en Action dans l'Ère du Développement

Dans les années 1950 au Brésil, au milieu de changements sociaux accélérés, on a entrepris d'importants projets collectifs de recherche en sciences sociales en partenariat avec des agences nationales et internationales intéressées par le développement régional. La coopération entre chercheurs et techniciens de la fonction publique était fondée sur le souhait que les études sociologiques et anthropologiques pourraient guider les transformations en cours. À partir de l'examen du programme de recherches de la Vallée du Rio São Francisco, on cherche, dans cet article, à saisir les inflexions de trajectoire du sociologue Donald Pierson, en y associant l'analyse du contexte et celle du contenu de sa production intellectuelle. Au départ, Pierson s'est concentré sur l'institutionnalisation des sciences sociales au Brésil, en proposant un modèle de travail sociologique calqué sur la recherche empirique. Mais, au cours de ses enquêtes dans la vallée du fleuve, il adopte une nouvelle perspective en incorporant au rôle de spécialiste sociologue celui d'agent du changement social, tout en soulignant l'importance de l'application du savoir sociologique.

Mots-clés: Donald Pierson, Projet du Vale do Rio São Francisco; développement; études de communautés; changement social; histoire des Sciences Sociales au Brésil 